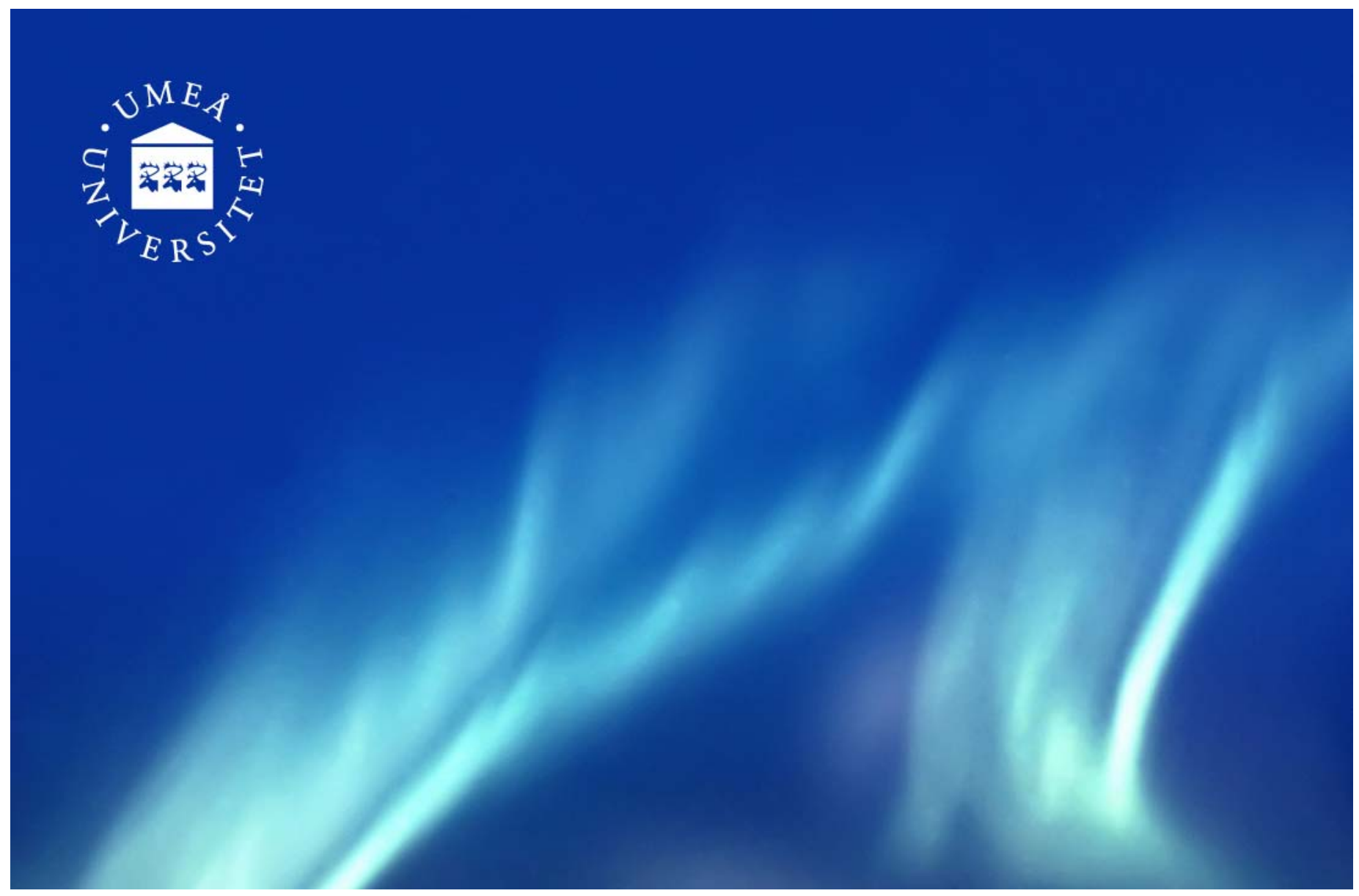

DiVA - Digitala Vetenskapliga Arkivet http://umu.diva-portal.org

This is a poster presented at European Multidisciplinary Cancer Congress, Stockholm, Sweden, 2327 September 2011.

Authors: Ringner, Anders; Jansson, Lilian; Hällgren Graneheim, Ulla

Title: Parental experiences of information within pediatric oncology 


\section{Parental Experiences of Information Within Paediatric Oncology}

Anders Ringnér (RN, MScN, PhD Student), Lilian Jansson (RNT, PhD, Associate Professor), Ulla Hällgren Graneheim (RNT, PhD, Associate Professor) Department of Nursing, Umeå University, Umeå, Sweden.

\section{Background}

Information is a key factor for parents of children with cancer that helps them create knowledge about their child's disease.

There are however obstacles to the acquisition of information, and the process has been described as similar to learning a new language.

By having information, the parents' sense of chaos can be reduced and a feeling of control and normality can be created.

\section{Aim}

The aim of this study was to describe parents' experiences of acquiring and using information to create knowledge about their child's cancer during the course of the illness.

\section{Methods}

14 parents of children with cancer participated in four focus group interviews.

After an initial qualitative content analysis of the interviews, we conducted an individual interview with one parent from each of the four focus groups. This data extended the analysis with individual accounts of the themes.

\section{This project...}

... is part of a larger project aimed at developing an information intervention for parents in paediatric oncology and is founded by the Swedish Childhood Cancer Foundation.

\section{Results}

Feeling acknowledged as

a person of significance

The parents felt safe and secure in spite of uncertainty when the information was well provided despite the emotional stress and chaos.

66They sat down and explained what it was and what they knew. So it was really a good thing to come to the ward. They took their time and I could ask my questions and talk about my thoughts and so on." (Father)

Having one's hopes supported was about the health care professionals conveying positive, reassuring information.

Getting relief from other families' experiences was important since other families acted as real-world examples and could help putting the parents' own situation in perspective.

66 And then you hear from other parents that it was like that for their children too, so they had to take it away." (Mother, talking about her child's troublesome gastric feeding tube)
Feeling like an

unwelcome guest

This theme was accentuated in later phases of the treatment.

Parents felt abandoned at important milestones such as at the first discharge or finishing treatment.

66 Well, I feel that when we return here after $2^{\frac{1}{2}}$ years, we should be greeted with a glass of champagne." (Mother)

Feeling forced to nag for information gave some parents a troubled conscience.

66Perhaps you need to hear that you really are welcome to ask questions and that it is all right. You are not a bother. Perhaps you need to hear that to feel that it is ok." (Mother)

Feeling burdened by the obligation to inform others was a paradoxical situation when parents had to keep the health care professionals informed instead of the other way around.

\section{Conclusions}

Clinicians should pay extra attention to parents at later stages in treatment and especially at important milestones such as treatment cessation. Also, providing continuous information meetings grounded in the parents' own needs would be valuable to parents. 